\title{
COMUNICACIÓN Y CREATIVIDAD EN LA COMPRENSIÓN DE LOS DERECHOS DEL NIÑO Y EL ADOLESCENTE EN ESTUDIANTES DEL SEGUNDO AÑO DE SECUNDARIA DEL COLEGIO PARTICULAR MUNDIAL DEL DISTRITO DE SAPALLANGA
}

\section{COMMUNICATION AND CREATIVITY IN THE UNDERSTANDING OF THE RIGHTS OF THE CHILD AND ADOLESCENT STUDENTS IN THE SECOND YEAR OF HIGH SCHOOL OF EL MUNDIAL SCHOOL SAPALLANGA DISTRICT}

\author{
Martha Marina Gómez Ferrer ${ }^{15}$ \\ Facultad de Ciencias de la Comunicación
}

\section{RESUMEN}

Para responder al problema de investigación: ¿Influyen adecuadamente los procesos de comunicación y creatividad en una adecuada comprensión de los derechos del niño y el adolescente?, fueron observados los procesos de comunicación y creatividad en la comprensión de los Derechos del Niño y el Adolescente en 20 estudiantes del Segundo Año de Secundaria del Colegio Particular Mundial del Distrito de Sapallanga; así como fueron aplicados el cuestionario antes y después de los proceso, y los registros de observación. El estudio de nivel explicativo y de tipo aplicado, utiliza la metodología cualitativa para posibilitar la comprensión de las variables de estudio: Variable independiente: Procesos comunicativo y creativo, y de la variable dependiente: Comprensión de los derechos del niño y el adolescente; comprobándose la hipótesis de investigación: Los procesos comunicativo y creativo permiten la comprensión de los derechos del niño y el adolescente en Estudiantes del Segundo Año de Secundaria Colegio Particular Mundial del Distrito de Sapallanga. Los resultados demuestran que los estudiantes en un $25 \%$ del total incrementaron la comprensión de sus derechos, a través del proceso creativo de elaboración y discusión de historias y mediante la interacción en la comunicación entre los participantes.

Palabras clave: proceso comunicativo y creativo

\section{ABTRACT}

To answer the research question: Do the communication process and creativity influence properly in a proper understanding of the rights of children and adolescents?, Were observed communication processes and creativity in understanding the rights of the child and adolescent among 20 students of high school second level of the Mundial private school of Sapallanga district as well as the questionnaire was applied before and after the process and observation records. The study of explanation level and applied type, using qualitative methodology to enable an understanding of the variables of study: Independent variable: communicative and creative processes, and the dependent variable: Children and adolescents rights understanding; checking research hypothesis: communicative and creative processes allow the understanding of the rights of children and adolescents in second year students of Mundial private high school, Sapallanga district. The results show that students in a $25 \%$ increased the understanding of their rights, through the creative process of drafting and discussion of stories and through interaction among participants.

Key words: communicative and creative process.

\footnotetext{
${ }^{15}$ mgomezferrer@hotmail.com
} 


\section{INTRODUCCIÓN}

Los derechos del niño y del adolescente requieren contar con estudios que permitan la mejor comprensión y es a través de los procesos de creatividad y de comunicación que las personas se involucran posibilitando el desarrollo de su comprensión con respecto al mundo que los rodea.

Es mediante la creatividad y la comunicación que les permite a los adolescentes desarrollar nuevas habilidades como explorar su imaginación en la soluciones nuevas a los problemas, facilitando respuestas en defensa de sus derechos. Asimismo, entablar mejores interrelaciones con sus compañeros del aula, profesores, familia y su entorno en lo que a sus derechos se refiere.

Para mejorar los niveles de comprensión de sus derechos en los estudiantes del segundo de secundaria del Colegio Particular Mundial de Sapallanga, a través de los procesos comunicativo y creativo, objetivo de la investigación, fueron aplicados los cuestionarios y registros de observación a 20 estudiantes, determinándose por los resultados que un $25 \%$ del total de estudiantes incrementaron su comprensión de los derechos del niño y del adolescente mediante la elaboración, discusión, dramatización de sus historias y reflexión en las fases cuestionamiento, acopio de datos; incubación, iluminación, elaboración y comunicación.

De otro lado, mediante el registro de observación se ha establecido los niveles de gestos no verbales, actitudes de escucha al interlocutor, expresiones verbales y participación en los grupos de trabajo.

En tal sentido, presentó al lector los logros obtenidos en la presente investigación que sin lugar a dudas, constituye una valiosa ayuda para toda aquella persona que quiere profundizar en el empleo de los procesos de creatividad y comunicación para mejorar los niveles de comprensión de los derechos del niño y del adolescente.

\section{MATERIAL Y MÉTODOS}

La presente investigación de nivel explicativo y de tipo aplicada, utiliza el método inductivo, siendo una investigación eminentemente cualitativa, y como materiales empleó tanto para el marco teórico como para la discusión libros, investigaciones y publicaciones.

Para posibilitar la comprensión y análisis de las variables de estudio. Variable independiente:: Procesos comunicativo y creativo, y de la Variable dependiente: Comprensión de los derechos del niño y el adolescente, se procedió a revisar el material informativo, reflexionando de manera inductiva y generando ideas en base a las hipótesis de estudio para obtener conclusiones.

\section{RESULTADOS Y DISCUSIÓN}

\section{Interacción comunicativa de los estudiantes}

En la interacciön comunicativa entre las estudiantes durante el desarrollo de la elaboración de las historias y del debate de las mismas, por los registros de observación de sus gestos no verbales, se cuenta que el $75 \%$ de estudiantes miran con atención cuando sus compañeros intervienen. Manifiestan expresiones faciales de interés. Esta expresión no verbal posibilita que el sistema de comunicación se retroalimente a través del diálogo.

Contrariamente a estas actitudes de interés en las expresiones no verbales se encuentra que el $25 \%$ de los estudiantes por sus actitudes y gestos faciales denotan distracciones. Miran a su alrededor, agachan la cabeza, y miran su cuaderno, el suelo o la ventana. Entre los gestos de desinterés encontramos algunos de disgusto y expresiones no verbales de temor. Estas actitudes perjudican el flujo y desenvolvimiento de la comunicación creando por momentos 
silencio en el grupo y cierto temor a decir las cosas ante la posibilidad de equivocarse.

En lo referente a las actitudes de recepción de mensajes, en momentos en que sus compañeros aportan en la construcción de las historia y en el debate de las mismas, se observa que el $75 \%$ de los estudiantes que manifiestan actitudes interés, son los mismos que muestran actitudes de atención. En cambio los estudiantes manifiestan desinterés por el trabajo grupal $25 \%$, son los que se distraen.

En la elaboración, representación y reflexión de las historias, se observa que un $80 \%$ sus manifestaciones están referidas a expresiones verbales positivas: de amabilidad, respeto, serviciales y de entusiasmo lo que demuestran que mantienen buenas interrelaciones con sus compañeros. Estos estudiantes se mantienen abiertos en sus conversaciones y no se molestan cuando le hacen preguntas personales; ni se enojan cuando sus compañeras no comparten sus opiniones, esta apertura en la comunicación hace posible seguir retroalimentando el sistema de comunicación haciendo que ésta sea más fluida y que exista mayor confianza en sus interrelaciones.

Por el contrario, se observa que un $20 \%$ de estudiantes no cuentan con una buena interrelación con sus compañeros, mostrándose en sus palabras negativas, cortantes, dominantes y enojadas. Así son persistentes en imponer sus ideas, desconfiados, y se enojan cuando les hacen preguntas personales y se niegan que el trabajo puede salir bien, demostrando que desarrollan inadecuadas interrelaciones que ocasionan bloqueos en el flujo de la comunicación, debido a que las opiniones fijas y cerradas perjudican el desenvolvimiento de la comunicación en el grupo.

En la elaboración, representación y reflexión de las historias, el grado de participación es importante en la apertura dialógica para la comprensión de los derechos del niño y del adolescente. Se observa al respecto que un significativo porcentaje, el $60 \%$ de estudiantes participan con más de dos intervenciones, posibilitando el desenvolvimiento y aprendizaje del tema a través del diálogo. El $30 \%$ de estudiantes en el grupo participan con dos intervenciones en el desarrollo del trabajo grupal de aprendizaje. En cambio el $5 \%$ presenta una sola intervención y un porcentaje similar no interviene, en la reflexión de la historia, evidenciando la presencia de problemas personales. (ver cuadro $\mathrm{N}^{0} 1$ en anexo) 


\section{Cuadro $\mathrm{N}^{0} 1$}

Comunicación y participación

\begin{tabular}{|c|c|c|c|c|}
\hline Categoría & Subcategoría & Indicadores & Cantidad & Porcentaje \\
\hline $\begin{array}{l}\text { Elaboración de las } \\
\text { historias } \\
\text { Representación de } \\
\text { las historias } \\
\text { Reflexión de las } \\
\text { historias }\end{array}$ & $\begin{array}{l}\text { Gestos no } \\
\text { verbales }\end{array}$ & $\begin{array}{l}\text { Interés } \\
\text { Desinterés }\end{array}$ & $\begin{array}{l}15 \\
5\end{array}$ & $\begin{array}{l}75 \% \\
25 \%\end{array}$ \\
\hline $\begin{array}{l}\text { Elaboración de las } \\
\text { historias } \\
\text { Representación de } \\
\text { las historias } \\
\text { Reflexión de las } \\
\text { historias }\end{array}$ & $\begin{array}{l}\text { Actitudes cuando } \\
\text { el interlocutor } \\
\text { interviene }\end{array}$ & $\begin{array}{l}\text { Atención } \\
\text { distracción }\end{array}$ & $\begin{array}{l}15 \\
5\end{array}$ & $\begin{array}{l}75 \% \\
25 \%\end{array}$ \\
\hline \multirow[t]{2}{*}{$\begin{array}{l}\text { Elaboración de las } \\
\text { historias } \\
\text { Representación de } \\
\text { las historias } \\
\text { Reflexión de las } \\
\text { historias }\end{array}$} & $\begin{array}{l}\text { Expresiones } \\
\text { empleadas en el } \\
\text { trabajo en grupo }\end{array}$ & $\begin{array}{l}\text { Expresiones } \\
\text { positivas: } \\
\text { Amables, } \\
\text { serviciales, } \\
\text { respeto, } \\
\text { entusiasmo. }\end{array}$ & 16 & $80 \%$ \\
\hline & & $\begin{array}{l}\text { Expresiones } \\
\text { negativas: } \\
\text { cortante, } \\
\text { dominante, de } \\
\text { enojo y } \\
\text { agresivas. }\end{array}$ & 4 & $20 \%$ \\
\hline Elaboración de las & Participación & No interviene & 1 & $5 \%$ \\
\hline historias & & Una & 1 & $5 \%$ \\
\hline $\begin{array}{l}\text { Representación de } \\
\text { las historias } \\
\text { Reflexión de las }\end{array}$ & & $\begin{array}{l}\text { Intervención } \\
\text { Dos } \\
\text { intervenciones }\end{array}$ & 6 & $30 \%$ \\
\hline historias & & $\begin{array}{l}\text { Más de dos } \\
\text { intervenciones }\end{array}$ & 12 & $60 \%$ \\
\hline
\end{tabular}

Fuente: Registro de observación a 20 estudiantes

Proceso creativo en la comprensión de los derechos del niño y los adolescentes.

A nivel de grupo se procedió a medir las distintas fases del proceso creativo para determinar su influencia en la comprensión de los derechos del niño y del adolescente.

Para las fases de cuestionamiento y acopio de datos:

Se les mostró a los participantes, videos de los derechos del niño

Se les pidió voluntarios que cuente su experiencia de un derecho de los mostrados en los videos, que en su caso es vulnerado.
Se pidió voluntarios que cuente su experiencia de ese mismo maltrato que han visto en su barrio o comunidad, con la finalidad de que los estudiantes perciban que su problema no es personal sino social.

En la primera fase de cuestionamiento, después que los grupos deliberaron cinco historias que reflejan los problemas que les afectan en sus vidas con respecto a la vulneración de sus derechos, se obtuvo como resultado que el $80 \%$ de historias se obtuvo respuesta. Estas están referidas al: Derecho a la vida; a la igualdad; a vivir en un medio ambiente saludable y derechos a ser bien tratados. En cambio el $20 \%$, una historia no obtuvo respuesta es la referida al derecho a 
la salud, pues el tratamiento es superficial. En esta fase se requiere direccionalidad de nuestra mente hacia encontrar las respuestas de un determinado asunto y también de la reflexión.

En la siguiente fase de acopio de datos, se encontró que el $80 \%$ de estudiantes exploró casos de violación de los derechos humanos a través de las observaciones e información. El hurgar sobre un problema permite encontrar las posibles soluciones, haciendo funcionar la mente creativa para encontrar la pistas necesarias que ayuden a crear nuevas situaciones sobre bases sólidas. En un menor porcentaje el $20 \%$, un grupo de cinco alumnos, no exploraron adecuadamente ni reflexionaron sobre el derecho de la salud en sus vidas. (Ver cuadro $\mathrm{N}^{0} 2$ en anexo)

Para la fase de incubación, se conformaron grupos de cinco y se les dio las instrucciones para crear la historia. Cada grupo recortó cuatro imágenes significativas de un periódico, relacionadas con un derecho que en la experiencia de la mayoría del grupo es vulnerado y que fueron ser pegadas en papel bond.

Acerca de la fase de incubación, el $80 \%$ se centro en el problema de su realidad, entretejiendo en el inconsciente de manera silenciosa y manteniendo la mente centrada en la direccionalidad elegida de encontrar respuestas de asociaciones para la elaboración de los argumentos de su propia historia. En cambio el $20 \%$,de estudiantes no se centro en el problema por que presentaron sin ninguna relación la representación de cuatro imágenes y sin ninguna vinculación con su experiencia de vida. (Ver cuadro $\mathrm{N}^{\circ} 2$ en anexo).

Al respecto de las fases de inspiración y elaboración, éstas no se dan de manera aisladas. Por ejemplo la fase de elaboración esta interrelacionada con la inspiración. Se les pidió a los estudiantes:

En diez minutos que enlacen las imágenes seleccionadas, y con su imaginación y experiencia creen la historia y las escenas.
Cada grupo salió a representar en dramatización su historia de derecho vulnerado. Al final cuentan que piensan al respecto y cómo se han sentido al respecto.

Se les dio otros diez minutos para que cada grupo trabaje con su historia, dibujando la creación de nuevas escenas, pero esta vez dando la solución al problema y se logre el respeto del derecho, que en la historia anterior había sido vulnerado.

Los resultados son precisos respecto a la fase de inspiración, el 80\% logró respuestas a la solución de problemas, respecto a la vulneración de sus derechos, a partir de sus propias experiencias de vida, acerca del derecho a la vida, a la igualdad, a vivir en un medio ambiente saludable y derecho a ser bien tratados. Contrariamente el $20 \%$, referido a un solo grupo no logró la fase de inspiración, toda vez que no llevaron adecuadamente las fases anteriores que posibilita la creatividad, así no lograron ninguna solución al problema de salud. (Ver cuadro $\mathrm{N}^{\circ} 2$ en anexo).

Finalmente se llegó a la fase de comunicación, referida a la presentación y reflexión colectiva de las dramatizaciones realizadas por cada uno de los grupos. Esta fase comprende el momento de su expansión y el compartir los frutos de su creación con los demás compañeros fuera del grupo.

En el momento de la comunicación, cada grupo salió a representar en dramatización su nueva historia del derecho respetado. Al final cada grupo contó lo que piensan del problema. Así el $80 \%$ de los grupos reflexionó lo que piensan del problema, que situaciones llevaron a la solución del mismo y cómo se sintieron cuando hicieron valer y respetar sus derechos. Solo un grupo que constituye el $20 \%$ no cumplió con esta fase, ya que no presentaron en sus dramatizaciones ninguna solución a la problemática de su derecho vulnerado. Se abocaron a repetir una misma historia incoherente, que no expresa cambio alguno. (Ver cuadro $\mathrm{N}^{0} 2$ en anexo). 
Cuadro $N^{0}$ 2.- proceso creativo

\begin{tabular}{|c|c|c|c|c|}
\hline Categoría & Subcategoria & Indicadores & Cantidad & Porcentaje \\
\hline \multirow{12}{*}{$\begin{array}{l}\text { Fases del } \\
\text { proceso } \\
\text { creativo }\end{array}$} & Cuestionamiento & Existe respuesta & 4 & $80 \%$ \\
\hline & & No existe respuesta & 1 & $20 \%$ \\
\hline & Acopio de datos & Explora el problema & 4 & $80 \%$ \\
\hline & & No explora el problema & 1 & $20 \%$ \\
\hline & Incubación & Se centra en el problema & 4 & $80 \%$ \\
\hline & & No se centra en el problema & 1 & $20 \%$ \\
\hline & Inspiración & Se encontró la solución & 4 & $80 \%$ \\
\hline & & No se encontró la solución & 1 & $20 \%$ \\
\hline & Elaboración & $\begin{array}{lll}\text { Se representaron las } & \text { las } \\
\text { historias y soluciones } & \text { del } \\
\text { problema } & & \end{array}$ & 4 & $80 \%$ \\
\hline & & $\begin{array}{l}\text { Representan la historia pero } \\
\text { no la solución del problema }\end{array}$ & 1 & $20 \%$ \\
\hline & Comunicación & $\begin{array}{l}\text { Manifiestan y comparten con } \\
\text { otros sus hallazgos. }\end{array}$ & 4 & $80 \%$ \\
\hline & & $\begin{array}{l}\text { Manifiestan y Comparten } \\
\text { superficialmente su historia. }\end{array}$ & 1 & $20 \%$ \\
\hline
\end{tabular}

Fuente: Registro de observación del aplicado a cuatro grupos

\section{Antes y después del proceso creativo}

Es necesario señalar que antes de iniciar el proceso creativoy de observarel desenvolvimiento comunicativo de los participantes se aplicó un cuestionario referido a las siguientes preguntas a los 20 estudiantes participantes: ¿Qué derechos conoces?; ¿Qué derechos te son vulnerados o violentados?: ¿Qué situaciones deterioran tus derechos?; ¿Cuál sería la mejor solución al problema?, hay que destacar que el $50 \%$ de estudiantes reconocen menos de cinco derechos que les asiste; en tanto que el otro $50 \%$ reconocían más de cinco derechos; confirmándose que la mitad de alumnos reconocen la mayoría de sus derechos que les asisten: Derecho: a la vida; a la igualdad; a vivir en un medio ambiente saludable; a ser bien tratados; a tener una familia; a la asistencia médica y a la salud; a la recreación; a la educación; a la identidad y a la alimentación. Igualmente, reconocen más de dos derechos vulnerados, pueden reconocer situaciones que deterioran sus derechos y pueden encontrar soluciones a los problemas; mientras que un considerable $50 \%$ contrariamente reconocen menos de cinco derechos que les asiste; reconocen menos de dos derechos que les son vulnerados; no se percatan de situaciones que deterioran sus derechos, ni encuentran solución a sus problemas. (Ver cuadro №3 en anexo).

Después de culminarseconel proceso creativoyde comunicación se les volvió aplicar el cuestionario a los 20 estudiantes con las mismas preguntas, pudiéndose comprobar que la comprensión de los derechos del niño y del adolescente se vio favorecida en un $25 \%$ de alumnos que participaron activamente en el proceso creativo y de comunicación, quienes presentaron mejor disposición de comunicarse; toda vez que el $75 \%$ de estudiantes respondieron adecuadamente a todas las preguntas. Así cinco estudiantes que en su primer cuestionario no respondieron de acuerdo a los ítems de evaluación, después del proceso creativo reconocen más de cinco derechos que les asisten e indican más de dos 
derechos que les son vulnerados. Igualmente, pueden reconocer situaciones que deterioran sus derechos y pueden encontrar soluciones a los problemas. De esta manera, se comprobó que decreció el porcentaje del $50 \%$, al inicio de la aplicación de ambos procesos, al $25 \%$ de estudiantes que no respondieron adecuadamente a los ítems de evaluación del cuestionario. Este
$25 \%$ de incomprensión de sus derechos se dio en el caso de los cinco estudiantes que participaron en el grupo de los derechos de salud, cuyo contenido de su dramatización fue superficial y poco coherente; asimismo en los que presentan mayores dificultades en su comunicación y participación. (Ver cuadro $N^{0} 3$ en anexo).

Cuadro $\mathrm{N}^{0}$ 3.- Antes y después del proceso creativo y de comunicación

\begin{tabular}{|c|c|c|c|c|}
\hline & Pregunta & Indicadores & & Porcentaje \\
\hline \multirow[t]{8}{*}{ Antes } & $\begin{array}{l}\text { 1.- ¿Qué derechos } \\
\text { conoces? }\end{array}$ & $\begin{array}{l}\text { Reconocen más de cinco } \\
\text { derechos }\end{array}$ & 10 & $50 \%$ \\
\hline & & $\begin{array}{l}\text { Reconocen menos de cinco } \\
\text { derechos }\end{array}$ & 10 & $50 \%$ \\
\hline & 2.- ¿Qué derechos te son & Reconocen más de dos & 10 & $50 \%$ \\
\hline & vulnerados o violentados? & $\begin{array}{l}\text { derechos vulnerados } \\
\text { Reconocen menos de dos } \\
\text { derechos }\end{array}$ & 10 & $50 \%$ \\
\hline & 3.- ¿Qué situaciones & Reconocen situaciones que & 10 & $50 \%$ \\
\hline & deterioran tus derechos? & $\begin{array}{l}\text { deterioran sus derechos } \\
\text { No reconocen situaciones que } \\
\text { deterioran sus derechos }\end{array}$ & 10 & $50 \%$ \\
\hline & 4.- ¿Cuál sería la mejor & Encuentran la solución & 10 & $50 \%$ \\
\hline & solución al problema? & No se encontró la solución & 10 & $50 \%$ \\
\hline \multirow[t]{8}{*}{ Después } & $\begin{array}{l}\text { 1.- ¿Qué derechos } \\
\text { conoces? }\end{array}$ & $\begin{array}{l}\text { Reconocen más de cinco } \\
\text { derechos }\end{array}$ & 15 & $\begin{array}{l}75 \% \\
25 \%\end{array}$ \\
\hline & & $\begin{array}{l}\text { Reconocen menos de cinco } \\
\text { derechos }\end{array}$ & 5 & \\
\hline & 2.- ¿Qué derechos te son & Reconocen más de dos & 15 & $75 \%$ \\
\hline & vulnerados o violentados? & $\begin{array}{l}\text { derechos vulnerados } \\
\text { Reconocen menos de dos } \\
\text { derechos }\end{array}$ & 5 & $25 \%$ \\
\hline & 3.- ¿Qué situaciones & Reconocen situaciones que & 15 & $75 \%$ \\
\hline & deterioran tus derechos? & $\begin{array}{l}\text { deterioran sus derechos } \\
\text { No reconocen situaciones que } \\
\text { deterioran sus derechos }\end{array}$ & 5 & $25 \%$ \\
\hline & 4.- ¿Cuál sería la mejor & Encuentran la solución & 15 & $75 \%$ \\
\hline & solución al problema? & No se encontró la solución & 5 & $25 \%$ \\
\hline
\end{tabular}

Fuente: cuestionario aplicado antes y después a 20 estudiantes

\section{DISCUSIÓN}

Durante el desarrollo de la elaboración de las historias y del debate de las mismas, por sus gestos no verbales se cuenta que la mayoría de estudiantes miran con atención cuando sus compañeros intervienen. Manifiestan determinadas expresiones faciales de interés y atención, que como lo señala Davis, Flora (2006), constituyen códigos de comunicación no verbales que se dan en el diálogo, los mismos que se perciben mediante la observación, constituyendo la clave para entender la comunicación basada en la atención a los gestos, entre ellos los faciales.

Respecto a la comunicación verbal, ésta es eficaz como lo indica Davis, Flora para conocer las actitudes de las personas en la comunicación. En este sentido. la mayoría de estudiantes en su expresiones verbales manifiestan frases positivas, amables, de respeto y entusiasmo durante la elaboración, representación y 
reflexión de sus historias. Esta apertura en la comunicación hace posible seguir alimentándose el sistema de comunicación de manera positiva como lo especifica Berlo. David K. (1971) y hace posible que en la comunicación se de un proceso de aprendizaje humano, continuo sin bloqueos, toda vez que percibimos (decodificamos), interpretamos (hacemos de receptor y fuente) y emitimos una respuesta.

Al respecto, también el grado de socialización influye de manera directa tanto en las interrelaciones de comunicación entre los estudiantes como en la comprensión de los derechos del niño y del adolescente. Nos lo demuestra el significativo porcentaje de participación de más de dos intervenciones, dando lugar a la apertura dialógica para la comprensión de sus derechos y posibilitando el desenvolvimiento del diálogo en comprensión del tema a través del diálogo.

La investigación partió del enfoque de la teoría cognitiva de Corbalán, F.J. (1990) respecto al proceso creativo, En la primera y segunda fase referida al cuestionamiento y acopio de datos se obtuvieron respuestas, reflejando cada historia situaciones en sus vidas En estas fases se requiere direccionalidad de nuestra mente hacia encontrar las respuestas de un determinado asunto y también de la reflexión. Para el cognitivismo es de suma relevancia las actividades de búsqueda para el pensamiento creativo. Es así que el hurgar sobre un problema permite encontrar las posibles soluciones, haciendo funcionar la mente creativa para encontrar la pistas necesarias que ayuden a crear nuevas situaciones sobre bases sólidas.

El enfoque del cognitivismo en el proceso creativo sustenta la "búsqueda en amplitud" y "búsqueda en profundidad", según se trate de exploraciones. En este caso al procederse en la fase de incubación manteniendo la mente centrada en la direccionalidad elegida a fin de encontrar respuestas de asociaciones para la elaboración de los argumentos de su propia historias, la mayoría de estudiantes se ejercitaron en una búsqueda en profundidad, favoreciendo el proceso de comprensión de sus derechos al encontrar respuestas de asociaciones entre las imágenes para la elaboración de los argumentos de su propia historia.

Igualmente, el soporte teórico del cognitivismo que sostiene que las posibilidades que da a este nivel antes de pasar a la profundización en la dirección de la solución al problema fue la clave principal en la aplicación de las fases de iluminación, inspiración y elaboración, posibilitando que la mayoría de estudiantes encuentren respuestas precisas a la solución de los problemas de vulneración de sus derechos, a partir de sus propias experiencias de vida.

Como nos señala también el cognitivismo es hasta el final del proceso creativo que se puede verificar su eficacia. En este proceso el resultado final se evidencio en la última fase de comunicación en los que la mayoría de estudiantes expandieron y compartieron los frutos de su creación con los demás compañeros del aula. En el momento de la comunicación, cada grupo salió a representar en dramatización su nueva historia del derecho respetado, dando a conocer sus hallazgos de solución al problema.

\section{REFERENCIAS BIBLIOGRÁFICAS}

Berlo, David. El Proceso de la Comunicación, Introducción a la Teoría y a la Práctica, Editorial El Ateneo, Buenos Aires. 1971.

Davis, Flora. El lenguaje de los gestos. Eleven, Biblioteca del Nuevo tiempo, Rosario. 2006

Corbalán, F.J. Creatividad y procesos cognitivos. Tesis Doctoral. Universidad de Murcia. 1990. 